\title{
F-Convex Contraction via Admissible Mapping and Related Fixed Point Theorems with an Application
}

\author{
Y. Mahendra Singh ${ }^{1}(\mathbb{D})$, Mohammad Saeed Khan ${ }^{2}$ and Shin Min Kang ${ }^{3,4, *}$ \\ 1 Department of Humanities and Basic Sciences, Manipur Institute of Technology, Takyelpat 795004, India; \\ ymahenmit@rediffmail.com \\ 2 Department of Mathematics and Statistics, Sultan Qaboos University, P.O. Box 36, \\ Al-Khod Muscat 123, Oman; mohammad@squ.edu.om \\ 3 Department of Mathematics and RINS, Gyeongsang National University, Jinju 52828, Korea \\ 4 Center for General Education, China Medical University, Taichung 40402, Taiwan \\ * Correspondence:smkang@gnu.ac.kr
}

Received: 8 May 2018; Accepted: 5 June 2018; Published: 20 June 2018

\begin{abstract}
In this paper, we introduce $F$-convex contraction via admissible mapping in the sense of Wardowski [Fixed points of a new type of contractive mappings in complete metric spaces. Fixed Point Theory Appl., 94 (2012), 6 pages] which extends convex contraction mapping of type-2 of Istrăţescu [Some fixed point theorems for convex contraction mappings and convex non-expansive mappings (I), Libertas Mathematica, 1(1981), 151-163] and establish a fixed point theorem in the setting of metric space. Our result extends and generalizes some other similar results in the literature. As an application of our main result, we establish an existence theorem for the non-linear Fredholm integral equation and give a numerical example to validate the application of our obtained result.
\end{abstract}

Keywords: $\alpha$-admissible mapping; $\alpha^{*}$-admissible; $F$-contraction; $\alpha$-F-convex contraction; fixed point; non-linear Fredholm integral equation

\section{Introduction and Preliminaries}

The Banach's contraction principle [1] first appeared in explicit form in 1922, where it was used to establish the existence of a solution for an integral equation. Since then, because of its simplicity, usefulness and constructiveness, it has become a very popular and a fundamental tool in solving existence problems arising not only in pure and applied mathematics but also in many branches of sciences, engineering, social sciences, economics and medical sciences. One of the most common generalizations of Banach's contraction is the 1971's Ćirić contraction [2] (also see [3]), in that he considered all possible six values $d(x, y), d(x, T x), d(y, T y), d(x, T y), d(y, T x)$ and $d(T x, T y)$ by combining $x, y, T x, T y$ for all $x, y \in X$ and $T$ (self mapping on a metric space $(X, d)$ ). Later, in 1982, Istrăţescu [4] introduced the class of convex contractions in metric space, where he considered seven values $d(x, y), d(T x, T y), d(x, T x), d\left(T x, T^{2} x\right), d(y, T y), d\left(T y, T^{2} y\right)$ and $d\left(T^{2} x, T^{2} y\right)$ for all $x, y \in X$. Further, he showed with example (see Example 1.3, [4]) that $T$ is in the class of convex contraction but it is not a contraction. Recently, some researchers studied on generalization of such class of mappings in the setting of various spaces (for example, Alghamdi et al. [5], Ghorbanian et al. [6], Latif et al. [7], Miandaragh et al. [8], Miculescu [9], etc.). Khan et al. [10], introduced the notion of generalized convex contraction mapping of type- 2 by extending the generalized convex contraction (respectively, generalized convex contraction of order-2) of Miandaragh et al. [8] and the convex contraction mapping of type-2 of Istrăţescu [4]. Very recently, Khan et al. [11], discussed the notions of $(\alpha, p)$-convex contraction (respectively $(\alpha, p)$-contraction) and asymptotically $T^{2}$-regular (respectively $\left(T, T^{2}\right)$-regular) sequence and, showed that $(\alpha, p)$-convex contraction reduces to two-sided convex 
contraction [4]. Further, they have also shown with examples that the notions of asymptotically $T$-regular and $T^{2}$-regular sequences are independent to each other.

Generalizing the Banach contraction principle, Wardowski [12] introduced the notion of $F$-contraction and proved a new fixed point theorem concerning F-contractions.

Definition 1. [12] Let $F: R^{+} \rightarrow R$ be a mapping satisfying the following:

$\left(F_{1}\right) \quad F$ is strictly increasing, i.e., for all $\alpha, \beta \in R^{+}$such that $\alpha<\beta, F(\alpha)<F(\beta)$;

$\left(F_{2}\right)$ For each sequence $\left\{\alpha_{n}\right\}_{n \in N}$ of positive numbers $\lim _{n \rightarrow \infty} \alpha_{n}=0$ if and only if $\lim _{n \rightarrow \infty} F\left(\alpha_{n}\right)=-\infty$;

$\left(F_{3}\right)$ There exists $k \in(0,1)$ such that $\lim _{\alpha \rightarrow 0+} \alpha^{k} F(\alpha)=0$.

We denote $\mathcal{F}$, the set of all functions satisfying the above definition.

Definition 2. [12] A mapping $T: X \rightarrow X$ is said to be an F-contraction on $(X, d)$ if there exist $F \in \mathcal{F}$ and $\tau>0$ such that $\forall x, y \in X$,

$$
d(T x, T y)>0 \Rightarrow \tau+F(d(T x, T y)) \leq F(d(x, y)) .
$$

Example 1. [12] The following functions $F: \mathbb{R}^{+} \rightarrow \mathbb{R}$ are in $\mathcal{F}$.

(i) $F(\alpha)=\ln \alpha$;

(ii) $F(\alpha)=\ln \alpha+\alpha$;

(iii) $F(\alpha)=-\frac{1}{\sqrt{\alpha}}$;

(iv) $F(\alpha)=\ln \left(\alpha^{2}+\alpha\right)$.

By using F-contraction, Wardowski [12] proved a fixed point theorem which generalizes Banach's contraction principle in a different way than in the known results from the literature.

Theorem 1. [12] Let $(X, d)$ be a complete metric space and $T: X \rightarrow X$ be an F-contraction. Then, we have

(i) Thas a unique fixed point $z \in X$;

(ii) For all $x \in X$, the sequence $\left\{T^{n} x\right\}$ is convergent to $z \in X$.

Definition 3. ([2,3]) Let $(X, d)$ be a metric space and $T: X \rightarrow X$ be a mapping. Then, $T$ is said to be orbitally continuous on $X$ if $\lim _{i \rightarrow \infty} T^{n_{i}} x=z$ implies that $\lim _{i \rightarrow \infty} T^{n_{i}} x=T z$.

Let $T: X \rightarrow X$ be a mapping on a non-empty set $X$. We denote $\operatorname{Fix}(T)=\{x: T x=x$ for all $x \in X\}$.

Definition 4. [13] Let $T: X \rightarrow X$ be a self mapping on a non-empty set $X$ and $\alpha: X \times X \rightarrow[0, \infty)$ be a mapping, we say that $T$ is an $\alpha$-admissible if $x, y \in X, \alpha(x, y) \geq 1$ implies that $\alpha(T x, T y) \geq 1$.

Obviously, $\alpha(.,$.$) may or may not be symmetric and \alpha(x, y)=\alpha(y, x)$ (i.e., symmetric) if and only if $x=y$.

Definition 5. [14] Let $T: X \rightarrow X$ and $\alpha: X \times X \rightarrow(-\infty,+\infty)$. We say that $T$ is said to be a triangular $\alpha$-admissible if

$\left(T_{1}\right) \alpha(x, y)$ implies $\alpha(T x, T y) \geq 1, x, y \in X$;

$\left(T_{2}\right) \alpha(x, z) \geq 1$ and $\alpha(z, y) \geq 1$ imply $\alpha(x, y) \geq 1$ for all $x, y, z \in X$. (see for more examples Karapinar et al. [14]). 
Example 2. Let $X=[0, \infty)$. Define $T: X \rightarrow X$ and $\alpha: X \times X \rightarrow[0, \infty)$ by $T x=\ln (1+x)$ for all $x \in X$ and

$$
\alpha(x, y)= \begin{cases}1+x, & \text { if } x \geq y \\ 0, & \text { otherwise }\end{cases}
$$

Then, $T$ is $\alpha$-admissible as $\alpha(x, y) \geq 1$ implies that $\alpha(T x, T y) \geq 1$ for $x \geq y$ and $\alpha(x, y)=\alpha(y, x)$ for all $x=y$.

Definition 6. [15] Let $T$ be an $\alpha$-admissible mapping on a non-empty set $X$. We say that $X$ has the property $(H)$ if for each $x, y \in$ Fix $(T)$, there exists $z \in X$ such that $\alpha(x, z) \geq 1$ and $\alpha(y, z) \geq 1$.

Definition 7. An $\alpha$-admissible mapping $T$ is said to be an $\alpha^{*}$-admissible, if for each $x, y \in F i x(T) \neq \varnothing$, we have $\alpha(x, y) \geq 1$. If Fix $(T)=\varnothing$, we say that $T$ is vacuously $\alpha^{*}$-admissible.

The above definition is used by some authors without its nomenclature concerning the uniqueness of fixed point (for examples Alsulami et al. [16], Khan et al. [10], etc.).

Example 3. Let $X=[0, \infty)$. Define $T: X \rightarrow X$ and $\alpha: X \times X \rightarrow[0, \infty)$ by $T x=1+x$ for all $x \in X$ and

$$
\alpha(x, y)= \begin{cases}e^{2(x-y)}, & \text { if } x \geq y \\ 0, & \text { otherwise }\end{cases}
$$

Then, $T$ is $\alpha$-admissible. Since $T$ has no fixed point, i.e., Fix $(T)=\varnothing$, so $T$ is vacuously $\alpha^{*}$-admissible.

Example 4. Let $X=[0, \infty)$. Define $T: X \rightarrow X$ and $\alpha: X \times X \rightarrow[0, \infty)$ by $T x=\frac{x^{2}}{2}$ for all $x \in X$ and

$$
\alpha(x, y)= \begin{cases}1, & \text { if } x, y \in[0,2] \\ 0, & \text { otherwise. }\end{cases}
$$

Obviously, $T$ is $\alpha$-admissible and Fix $(T)=\{0,2\}$. Then, $T$ is $\alpha^{*}$-admissible

Example 5. Let $X=[0, \infty)$. Define $T: X \rightarrow X$ and $\alpha: X \times X \rightarrow[0, \infty)$ by $T x=\sqrt{\frac{x\left(x^{2}+2\right)}{3}}$ for all $x \in X$ and

$$
\alpha(x, y)= \begin{cases}1, & \text { if } x, y \in[0,1] \\ 0, & \text { otherwise. }\end{cases}
$$

Obviously, $T$ is $\alpha$-admissible and $\operatorname{Fix}(T)=\{0,1,2\}$. Note that $T$ is not an $\alpha^{*}$-admissible, since $\alpha(x, 2)=0$ for $x \in\{0,1\}$.

In the next section, we extend the notion of convex contraction [4] to an $\alpha$-F-convex contraction and prove a fixed point theorem in the setting of metric space.

\section{2. $\alpha-F$-Convex Contraction}

In this section, we discuss the class of $\alpha-F$-convex contractions. Let $T$ be a mapping on a metric space $(X, d)$. We denote

$$
\begin{aligned}
M^{p}(x, y)=\max & \left\{d^{p}(x, y), d^{p}(T x, T y), d^{p}(x, T x), d^{p}\left(T x, T^{2} x\right), d^{p}(y, T y),\right. \\
& \left.d^{p}\left(T y, T^{2} y\right)\right\} .
\end{aligned}
$$


Definition 8. A self mapping $T$ on $X$ is said to be an $\alpha$-F-convex contraction, if there exist two functions $\alpha: X \times X \rightarrow[0, \infty)$ and $F \in \mathcal{F}$ such that

$$
d^{p}\left(T^{2} x, T^{2} y\right)>0 \Rightarrow \tau+F\left(\alpha(x, y) d^{p}\left(T^{2} x, T^{2} y\right)\right) \leq F\left(M^{p}(x, y)\right)
$$

for all $x, y \in X$ where $p \in[1, \infty)$ and $\tau>0$.

Example 6. Let $F(\gamma)=\ln (\gamma), \gamma>0$. Obviously, $F \in \mathcal{F}$. Let $T: X \rightarrow X$ be a self mapping on a metric space $(X, d)$. Consider the convex contraction of type-2 (Istrăţescu [4]) taking with $\alpha(x, y)=1$ for all $x, y \in X$, $e^{-\tau}=k=\sum_{i=1}^{6} \alpha_{i}<1$ and $\alpha_{i} \geq 0$ for all $i=1,2, \ldots, 6$.

$$
\begin{aligned}
d\left(T^{2} x, T^{2} y\right) \leq & \alpha_{1} d(x, y)+\alpha_{2} d(T x, T y)+\alpha_{3} d(x, T x)+\alpha_{4} d\left(T x, T^{2} x\right) \\
& +\alpha_{5} d(y, T y)+\alpha_{6} d\left(T y, T^{2} y\right)
\end{aligned}
$$

where $x, y \in X$ with $x \neq y$. Then, we obtain

$$
\begin{aligned}
\alpha(x, y) d\left(T^{2} x, T^{2} y\right)= & d\left(T^{2} x, T^{2} y\right) \\
\leq & \sum_{i=1}^{6} \alpha_{i} \max \{d(x, y), d(T x, T y), d(x, T x) \\
& \left.d\left(T x, T^{2} x\right), d(y, T y), d\left(T y, T^{2} y\right)\right\}
\end{aligned}
$$

which implies that

$$
\alpha(x, y) d\left(T^{2} x, T^{2} y\right) \leq k M^{1}(x, y)=e^{-\tau} M^{1}(x, y) .
$$

Taking natural logarithm on both sides, we obtain

$$
\tau+F\left(\alpha(x, y) d\left(T^{2} x, T^{2} y\right)\right) \leq F\left(M^{1}(x, y)\right) .
$$

Therefore,

$$
d\left(T^{2} x, T^{2} y\right)>0 \Rightarrow \tau+F\left(\alpha(x, y) d\left(T^{2} x, T^{2} y\right)\right) \leq F\left(M^{1}(x, y)\right)
$$

for all $x, y \in X$. This shows that $T$ is an $\alpha-F$-convex contraction with $p=1$.

Example 7. Let $X=[0,1]$ with usual metric $d(x, y)=|x-y|$. Define a mapping $T: X \rightarrow X$ by $T x=\frac{x^{2}}{2}+\frac{1}{4}$ for all $x \in X$ with $\alpha(x, y)=1$ for all $x, y \in X$. Then, $T$ is $\alpha$-admissible. Further, we see that $T$ is non-expansive, since we have

$$
|T x-T y|=\frac{1}{2}\left|x^{2}-y^{2}\right| \leq|x-y| \text { for all } x, y \in X .
$$

Setting $F \in \mathcal{F}$ such that $F(\gamma)=\ln \gamma, \gamma>0$. Then, for all $x, y \in X$ with $x \neq y$, we obtain

$$
\begin{aligned}
\alpha(x, y)\left|T^{2} x-T^{2} y\right| & =\left|T^{2} x-T^{2} y\right| \\
& =\frac{1}{8}\left(\left|\left(x^{4}+x^{2}\right)-\left(y^{4}+y^{2}\right)\right|\right) \\
& \leq \frac{1}{8}\left(\left|x^{4}-y^{4}\right|+\left|x^{2}-y^{2}\right|\right) \\
& \leq \frac{1}{2}|T x-T y|+\frac{1}{4}|x-y| \\
& \leq \frac{3}{4} \max \{|T x-T y|,|x-y|\} \\
& \leq e^{-\tau} M^{1}(x, y) \leq e^{-\tau} M^{1}(x, y)
\end{aligned}
$$


where $-\tau=\ln \left(\frac{3}{4}\right)$. Taking natural logarithm on both sides, we obtain

$$
\tau+F\left(\alpha(x, y) d\left(T^{2} x, T^{2} y\right)\right) \leq F\left(M^{1}(x, y)\right) .
$$

This shows that $T$ is an $\alpha$-F-convex contraction with $p=1$.

Example 8. Let $T: X \rightarrow X$, where $X=[0,1]$ with usual metric $d(x, y)=|x-y|$. Define $T x=\frac{1-x^{2}}{2}$, for all $x \in X$ and $\alpha(x, y)=1$ for all $x, y \in X$. Then, $T$ is $\alpha$-admissible. Setting $F \in \mathcal{F}$ such that $F(\gamma)=\ln \gamma, \gamma>0$. Then, for all $x, y \in X$ with $x \neq y$, we obtain

$$
|T x-T y|=\frac{1}{2}\left|x^{2}-y^{2}\right| \leq|x-y|
$$

and

$$
\begin{aligned}
\alpha(x, y)\left|T^{2} x-T^{2} y\right| & =\frac{1}{8}\left(\left|\left(2 x^{2}-x^{4}\right)-\left(2 y^{2}-y^{4}\right)\right|\right) \\
& =\frac{1}{8}\left(2\left|x^{2}-y^{2}\right|+\left|x^{4}-y^{4}\right|\right) \\
& \leq \frac{1}{2}|x-y|+\frac{1}{4}\left|x^{2}-y^{2}\right| \\
& =\frac{1}{2}|x-y|+\frac{1}{2}|T x-T y| \\
& \leq \max \{|x-y|,|T x-T y|\} \\
& \leq M^{1}(x, y)
\end{aligned}
$$

Taking natural logarithm on both sides, we obtain

$$
F\left(\alpha(x, y) d\left(T^{2} x, T^{2} y\right)\right) \leq F\left(M^{1}(x, y)\right) .
$$

However, there does not exist $\tau>0$ such that

$$
\tau+F\left(\alpha(x, y) d\left(T^{2} x, T^{2} y\right)\right) \leq F\left(M^{1}(x, y)\right) .
$$

Therefore, $T$ is not an $\alpha$-F-convex contraction with $p=1$. Also, consider

$$
|T x-T y|^{2}=\frac{1}{4}\left|x^{2}-y^{2}\right|^{2} \leq|x-y|^{2}
$$

and

$$
\begin{aligned}
\alpha(x, y)\left|T^{2} x-T^{2} y\right|^{2} & =\frac{1}{64}\left|\left(2 x^{2}-x^{4}\right)-\left(2 y^{2}-y^{4}\right)\right|^{2} \\
& \leq \frac{1}{64}\left(4\left|x^{2}-y^{2}\right|^{2}+\left|x^{4}-y^{4}\right|^{2}\right) \\
& =\frac{1}{16}\left|x^{2}-y^{2}\right|^{2}+\frac{1}{64}\left|x^{4}-y^{4}\right|^{2} \\
& \leq \frac{1}{4}|x-y|^{2}+\frac{1}{16}\left|x^{2}-y^{2}\right|^{2} \\
& \leq \frac{5}{16} \max \left\{|x-y|^{2},|T x-T y|^{2}\right\} \\
& =\frac{5}{16} M^{2}(x, y)=e^{-\tau} M^{2}(x, y) .
\end{aligned}
$$


Taking natural logarithm on both sides, we obtain

$$
\tau+F\left(\alpha(x, y) d\left(T^{2} x, T^{2} y\right)\right) \leq F\left(M^{2}(x, y)\right)
$$

where $-\tau=\ln \frac{5}{16}$. Therefore, $T$ is an $\alpha-F$-convex contraction with $p=2$.

\section{Fixed Point Results of an $\alpha-F$-Contraction}

We prove the following lemma which will be used in the sequel.

Lemma 1. Let $(X, d)$ be a metric space and $T: X \rightarrow X$ be an $\alpha-F$-convex contraction satisfying the conditions:

(i) $T$ is $\alpha$-admissible;

(ii) there exists $x_{0} \in X$ such that $\alpha\left(x_{0}, T x_{0}\right) \geq 1$.

Define a sequence $\left\{x_{n}\right\}$ in $X$ by $x_{n+1}=T x_{n}=T^{n+1} x_{0}$ for all $n \geq 0$, then $F\left(d^{p}\left(x_{n}, x_{n+1}\right)\right) \leq F(v)-l \tau$, whenever $n=2 l$ or $n=2 l+1$ for $l \geq 1$.

Proof. Following the same steps as in Lemma 1, the last paragraph was replaced with the following: Therefore, $v>d^{p}\left(x_{2}, x_{3}\right)$ and hence $F\left(d^{p}\left(x_{2}, x_{3}\right)\right) \leq F(v)-\tau$. By a similar argument, we obtain $F\left(d^{p}\left(x_{3}, x_{4}\right)\right) \leq F(v)-\tau$; continuing in these way, we arrive at $F\left(d^{p}\left(x_{n}, x_{n+1}\right)\right) \leq F(v)-l \tau$, whenever $n=2 l$ or $n=2 l+1$ for $l \geq 1$.

Proof. Let $x_{0} \in X$ be such that $\alpha\left(T x_{0}, x_{0}\right) \geq 1$ and $\left\{x_{n}\right\}$ is a sequence defined by $x_{n+1}=T x_{n}$ for all $n \in \mathbb{N} \cup\{0\}$. Since $T$ is $\alpha$-admissible, $\alpha\left(x_{0}, x_{1}\right)=\alpha\left(x_{0}, T x_{0}\right) \geq 1$ implies that $\alpha\left(x_{2}, x_{3}\right)=$ $\alpha\left(T x_{1}, T^{2} x_{0}\right) \geq 1$. One can obtain inductively that $\alpha\left(x_{n}, x_{n+1}\right) \geq 1$ for all $n \geq 0$. Assume that $x_{n} \neq x_{n+1}$ for all $n \geq 0$. Then, $d\left(x_{n}, x_{n+1}\right)>0$ for all $n \geq 0$. Setting $v=\max \left\{d^{p}\left(x_{0}, x_{1}\right), d^{p}\left(x_{1}, x_{2}\right)\right\}$. From (2), taking $x=x_{0}$ and $y=x_{1}$, we obtain

$$
\begin{aligned}
M^{p}\left(x_{0}, x_{1}\right)= & \max \left\{d^{p}\left(x_{0}, x_{1}\right), d^{p}\left(T x_{0}, T x_{1}\right), d^{p}\left(x_{0}, T x_{0}\right),\right. \\
& \left.d^{p}\left(T x_{0}, T^{2} x_{0}\right), d^{p}\left(x_{1}, T x_{1}\right), d^{p}\left(T x_{1}, T^{2} x_{1}\right)\right\} \\
= & \max \left\{d^{p}\left(x_{0}, x_{1}\right), d^{p}\left(x_{1}, x_{2}\right), d^{p}\left(x_{0}, x_{1}\right),\right. \\
& \left.d^{p}\left(x_{1}, x_{2}\right), d^{p}\left(x_{1}, x_{2}\right), d^{p}\left(x_{2}, x_{3}\right)\right\} \\
= & \max \left\{d^{p}\left(x_{0}, x_{1}\right), d^{p}\left(x_{1}, x_{2}\right), d^{p}\left(x_{2}, x_{3}\right)\right\} .
\end{aligned}
$$

Since $F$ is strictly increasing and $\alpha\left(x_{0}, x_{1}\right) \geq 1$, by (3) and (4), we obtain

$$
\begin{aligned}
F\left(d^{p}\left(x_{2}, x_{3}\right)\right) & =F\left(d^{p}\left(T^{2} x_{0}, T^{2} x_{1}\right)\right) \\
& \leq F\left(\alpha\left(x_{0}, x_{1}\right) d^{p}\left(T^{2} x_{0}, T^{2} x_{1}\right)\right) \\
& \leq F\left(M^{p}\left(x_{0}, x_{1}\right)\right)-\tau \\
& =F\left(\max \left\{d^{p}\left(x_{0}, x_{1}\right), d^{p}\left(x_{1}, x_{2}\right), d^{p}\left(x_{2}, x_{3}\right)\right\}\right)-\tau \\
& \leq F\left(\max \left\{v, d^{p}\left(x_{2}, x_{3}\right)\right\}\right)-\tau .
\end{aligned}
$$

If $\max \left\{v, d^{p}\left(x_{2}, x_{3}\right)\right\}=d^{p}\left(x_{2}, x_{3}\right)$, then (5) gives

$$
F\left(d^{p}\left(x_{2}, x_{3}\right)\right) \leq F\left(d^{p}\left(x_{2}, x_{3}\right)\right)-\tau<F\left(d^{p}\left(x_{2}, x_{3}\right)\right) .
$$

This is a contradiction. It follows that

$$
F\left(d^{p}\left(x_{2}, x_{3}\right)\right) \leq F(v)-\tau<F(v)
$$


Since $\tau>0$ and $F$ is strictly increasing, it follows that

$$
d^{p}\left(x_{2}, x_{3}\right)<v=\max \left\{d^{p}\left(x_{0}, x_{1}\right), d^{p}\left(x_{1}, x_{2}\right)\right\} .
$$

Again, from (2) taking with $x=x_{1}$ and $y=x_{2}$, we obtain

$$
\begin{aligned}
M^{p}\left(x_{1}, x_{2}\right)= & \max \left\{d^{p}\left(x_{1}, x_{2}\right), d^{p}\left(T x_{1}, T x_{2}\right), d^{p}\left(x_{1}, T x_{1}\right),\right. \\
& \left.d^{p}\left(T x_{1}, T^{2} x_{1}\right), d^{p}\left(x_{2}, T x_{2}\right), d^{p}\left(T x_{2}, T^{2} x_{2}\right)\right\} \\
= & \max \left\{d^{p}\left(x_{1}, x_{2}\right), d^{p}\left(x_{2}, x_{3}\right), d^{p}\left(x_{1}, x_{2}\right),\right. \\
& \left.d^{p}\left(x_{2}, x_{3}\right), d^{p}\left(x_{2}, x_{3}\right), d^{p}\left(x_{3}, x_{4}\right)\right\} \\
= & \max \left\{d^{p}\left(x_{1}, x_{2}\right), d^{p}\left(x_{2}, x_{3}\right), d^{p}\left(x_{3}, x_{4}\right)\right\} .
\end{aligned}
$$

By (3) and (6), we obtain

$$
\begin{aligned}
F\left(d^{p}\left(x_{3}, x_{4}\right)\right) & =F\left(d^{p}\left(T^{2} x_{1}, T^{2} x_{2}\right)\right) \\
& \leq F\left(\alpha\left(x_{1}, x_{2}\right) d^{p}\left(T^{2} x_{1}, T^{2} x_{2}\right)\right) \\
& \leq F\left(M^{p}\left(x_{1}, x_{2}\right)\right)-\tau \\
& =F\left(\max \left\{d^{p}\left(x_{1}, x_{2}\right), d^{p}\left(x_{2}, x_{3}\right), d^{p}\left(x_{3}, x_{4}\right)\right\}\right)-\tau .
\end{aligned}
$$

If $\max \left\{d^{p}\left(x_{1}, x_{2}\right), d^{p}\left(x_{2}, x_{3}\right), d^{p}\left(x_{3}, x_{4}\right)\right\}=d^{p}\left(x_{3}, x_{4}\right)$, then we obtain

$$
F\left(d^{p}\left(x_{3}, x_{4}\right)\right) \leq F\left(d^{p}\left(x_{3}, x_{4}\right)\right)-\tau<F\left(d^{p}\left(x_{3}, x_{4}\right)\right) .
$$

This is again a contradiction. It follows that

$$
\max \left\{d^{p}\left(x_{1}, x_{2}\right), d^{p}\left(x_{2}, x_{3}\right)\right\}>d^{p}\left(x_{3}, x_{4}\right) .
$$

Therefore, $v>d^{p}\left(x_{2}, x_{3}\right)>d^{p}\left(x_{3}, x_{4}\right)$. Continuing in this process, one can prove inductively that $\left\{d^{p}\left(x_{n}, x_{n+1}\right)\right\}$ is a strictly non-increasing sequence in $X$.

Theorem 2. Let $(X, d)$ be a complete metric space and $T: X \rightarrow X$ be an $\alpha$-F-convex contraction satisfying the following conditions:

(i) $T$ is $\alpha$-admissible;

(ii) there exists $x_{0} \in X$ such that $\alpha\left(x_{0}, T x_{0}\right) \geq 1$;

(iii) $T$ is continuous or, orbitally continuous on $X$.

Then, $T$ has a fixed point in $X$. Further, if $T$ is $\alpha^{*}$-admissible, then $T$ has a unique fixed point $z \in X$. Moreover, for any $x_{0} \in X$ if $x_{n+1}=T^{n+1} x_{0} \neq T x_{n}$ for all $n \in \mathbb{N} \cup\{0\}$, then $\lim _{n \rightarrow \infty} T^{n} x_{0}=z$.

Proof. Let $x_{0} \in X$ be such that $\alpha\left(T x_{0}, x_{0}\right) \geq 1$ and define a sequence $\left\{x_{n}\right\}$ by $x_{n+1}=T x_{n}$ for all $n \in \mathbb{N} \cup\{0\}$. If $x_{n_{0}}=x_{n_{0}+1}$, i.e., $T x_{n_{0}}=x_{n_{0}}$ for some $n_{0} \in \mathbb{N} \cup\{0\}$, then $x_{n_{0}}$ is a fixed point of $T$.

Now, we assume that $x_{n} \neq x_{n+1}$ for all $n \geq 0$. Then, $d\left(x_{n}, x_{n+1}\right)>0$ for all $n \geq 0$. Since $T$ is $\alpha$-admissible, $\alpha\left(x_{0}, T x_{0}\right) \geq 1$ implies that $\alpha\left(x_{1}, x_{2}\right)=\alpha\left(T x_{0}, T^{2} x_{0}\right) \geq 1$. Therefore, one can obtain inductively that $\alpha\left(x_{n}, x_{n+1}\right)=\alpha\left(T^{n} x_{0}, T^{n+1} x_{0}\right) \geq 1$ for all $n \geq 0$. Setting $v=\max \left\{d^{p}\left(x_{0}, x_{1}\right), d^{p}\left(x_{1}, x_{2}\right)\right\}$. 
Now from (2), taking $x=x_{n-2}$ and $y=x_{n-1}$, where $n \geq 2$, we obtain

$$
\begin{aligned}
M^{p}\left(x_{n-2}, x_{n-1}\right)= & \max \left\{d^{p}\left(x_{n-2}, x_{n-1}\right), d^{p}\left(T x_{n-2}, T x_{n-1}\right), d^{p}\left(x_{n-2}, T x_{n-2}\right),\right. \\
& \left.d^{p}\left(T x_{n-2}, T^{2} x_{n-2}\right), d^{p}\left(x_{n-1}, T x_{n-1}\right), d^{p}\left(T x_{n-1}, T^{2} x_{n-1}\right)\right\} \\
= & \max \left\{d\left(x_{n-2}, x_{n-1}\right), d\left(x_{n-1}, x_{n}\right), d\left(x_{n-2}, x_{n-1}\right),\right. \\
& \left.\quad d^{p}\left(x_{n-1}, x_{n}\right), d^{p}\left(x_{n-1}, x_{n}\right), d^{p}\left(x_{n}, x_{n+1}\right)\right\} \\
= & \max \left\{d^{p}\left(x_{n-2}, x_{n-1}\right), d^{p}\left(x_{n-1}, x_{n}\right), d^{p}\left(x_{n}, x_{n+1}\right)\right\} .
\end{aligned}
$$

Since $F$ is strictly increasing and $T$ is $\alpha$-admissible, by (3), we obtain

$$
\begin{aligned}
F\left(d^{p}\left(x_{n}, x_{n+1}\right)\right) & =F\left(d^{p}\left(T^{2} x_{n-2}, T^{2} x_{n-1}\right)\right) \\
& \leq F\left(\alpha\left(x_{n-2}, x_{n-1}\right) d^{p}\left(T^{2} x_{n-2}, T^{2} x_{n-1}\right)\right) \\
& \leq F\left(M^{p}\left(x_{n-2}, x_{n-1}\right)-\tau\right. \\
& \leq F\left(\max \left\{d^{p}\left(x_{n-2}, x_{n-1}\right), d^{p}\left(x_{n-1}, x_{n}\right), d^{p}\left(x_{n}, x_{n+1}\right)\right\}\right)-\tau .
\end{aligned}
$$

If $\max \left\{d^{p}\left(x_{n-2}, x_{n-1}\right), d^{p}\left(x_{n-1}, x_{n}\right), d^{p}\left(x_{n}, x_{n+1}\right)\right\}=d^{p}\left(x_{n}, x_{n+1}\right)$, then we obtain

$$
F\left(d^{p}\left(x_{n}, x_{n+1}\right)\right) \leq F\left(d^{p}\left(x_{n}, x_{n+1}\right)\right)-\tau<F\left(d^{p}\left(x_{n}, x_{n+1}\right)\right) .
$$

This is a contradiction. Therefore,

$$
F\left(d^{p}\left(x_{n}, x_{n+1}\right)\right) \leq F\left(\max \left\{d^{p}\left(x_{n-2}, x_{n-1}\right), d^{p}\left(x_{n-1}, x_{n}\right)\right\}\right)-\tau
$$

By Lemma 1, we obtain:

$$
F\left(d^{p}\left(x_{n}, x_{n+1}\right)\right) \leq F(v)-l \tau,
$$

whenever $n=2 l$ or $n=2 l+1$ for $l \geq 1$.

From (6), we obtain

$$
\lim _{n \rightarrow \infty} F\left(d^{p}\left(x_{n}, x_{n+1}\right)\right)=-\infty .
$$

Therefore, by $\left(F_{2}\right)$ with $(8)$, we obtain

$$
\lim _{n \rightarrow \infty} d\left(x_{n}, x_{n+1}\right)=0
$$

From $\left(F_{3}\right)$, there exists $k \in(0,1)$ such that

$$
\lim _{n \rightarrow \infty}\left[d^{p}\left(x_{n}, x_{n+1}\right)\right]^{k} F\left(d^{p}\left(x_{n}, x_{n+1}\right)\right)=0 .
$$

Also, from (7), we obtain

$$
\left[d^{p}\left(x_{n}, x_{n+1}\right)\right]^{k}\left[F\left(d^{p}\left(x_{n}, x_{n+1}\right)\right)-F(v)\right] \leq-\left[d^{p}\left(x_{n}, x_{n+1}\right)\right]^{k} l \tau \leq 0,
$$

where $n=2 l$ or $n=2 l+1$ for $l \geq 1$.

Letting $n \rightarrow \infty$ in (11) together with (9) and (10), we obtain

$$
\lim _{n \rightarrow \infty} l\left[d\left(x_{n}, x_{n+1}\right)\right]^{k}=0
$$

Now, it arises in the following cases. 
Case-(i): If $n$ is even and $n \geq 2$, then from (12), we obtain

$$
\lim _{n \rightarrow \infty} n\left[d\left(x_{n}, x_{n+1}\right)\right]^{k}=0
$$

Case-(ii): If $n$ is odd and $n \geq 3$, then from (12), we obtain

$$
\lim _{n \rightarrow \infty}(n-1)\left[d\left(x_{n}, x_{n+1}\right)\right]^{k}=0 .
$$

Using (9), (14) gives

$$
\lim _{n \rightarrow \infty} n\left[d\left(x_{n}, x_{n+1}\right)\right]^{k}=0 .
$$

It may be observed from the above cases that, there exists $n_{1} \in \mathbb{N}$ such that

$$
n\left[d\left(x_{n}, x_{n+1}\right)\right]^{k} \leq 1 \quad \text { for all } n \geq n_{1}
$$

Therefore, we obtain

$$
d\left(x_{n}, x_{n+1}\right) \leq \frac{1}{n^{\frac{1}{k}}} \quad \text { for all } n \geq n_{1}
$$

Now, we show that $\left\{x_{n}\right\}$ is a Cauchy sequence. For all $p>q \geq n_{1}$, we obtain

$$
\begin{aligned}
d\left(x_{p}, x_{q}\right) & \leq d\left(x_{p}, x_{p-1}\right)+d\left(x_{p-1}, x_{p-2}\right)+\cdots+d\left(x_{q+1}, x_{q}\right) \\
& <\sum_{i=q}^{\infty} d\left(x_{i}, x_{i+1}\right) \leq \sum_{i=q}^{\infty} \frac{1}{i \frac{1}{k}}
\end{aligned}
$$

Since $\sum_{i=q}^{\infty} \frac{1}{i \frac{1}{k}}$ is convergent, taking $q \rightarrow \infty$, we get $\lim _{p, q \rightarrow \infty} d\left(x_{p}, x_{q}\right)=0$. This shows that $\left\{x_{n}\right\}$ is a Cauchy sequence in $X$. Since $X$ is complete, there exists $z \in X$ such that $\lim _{n \rightarrow \infty} x_{n}=z$. Now we prove that $z$ is a fixed point of $T$. Suppose $T$ is continuous, then

$$
d(z, T z)=\lim _{n \rightarrow \infty} d\left(x_{n}, T x_{n}\right)=\lim _{n \rightarrow \infty} d\left(x_{n}, x_{n+1}\right)=0 .
$$

This shows that $z$ is a fixed point of $T$.

Again, we suppose that $T$ is orbitally continuous on $X$, then $x_{n+1}=T x_{n}=T\left(T^{n} x_{0}\right) \rightarrow T z$ as $n \rightarrow \infty$. Since $(X, d)$ is complete this implies that $T z=z$. Therefore, $\operatorname{Fix}(T) \neq \varnothing$.

Further, we suppose that $T$ is $\alpha^{*}$-admissible, it follows that for all $z, z^{*} \in$ Fix $(T)$, we have $\alpha\left(z, z^{*}\right) \geq 1$. From (2) and (3), we obtain

$$
\begin{aligned}
F\left(d^{p}\left(z, z^{*}\right)\right)= & F\left(d^{p}\left(T^{2} z, T^{2} z^{*}\right)\right) \\
= & F\left(\alpha\left(z, z^{*}\right) d^{p}\left(T^{2} z, T^{2} z^{*}\right)\right) \\
\leq & F\left(M^{p}\left(z, z^{*}\right)\right)-\tau \\
= & F\left(\operatorname { m a x } \left\{d^{p}\left(z, z^{*}\right), d^{p}\left(T z, T z^{*}\right), d^{p}(z, T z), d^{p}\left(T z, T^{2} z\right),\right.\right. \\
& \left.\left.d^{p}\left(z^{*}, T z^{*}\right), d^{p}\left(T z^{*}, T^{2} z^{*}\right)\right\}\right)-\tau \\
= & F\left(d^{p}\left(z, z^{*}\right)\right)-\tau .
\end{aligned}
$$

Since $\tau>0$ and using $F$ is strictly increasing, we obtain

$$
F\left(d\left(z, z^{*}\right)\right)<F\left(d\left(z, z^{*}\right)\right)
$$

This is a contradiction. Therefore, $T$ has a unique fixed point in $X$. 
One can verify the validity of Theorem 2 with Examples 7 and 8 with proper choose of $\alpha(x, y)$ and $p$.

Corollary 1. Let $(X, d)$ be a complete metric space and $\alpha: X \times X \rightarrow[0, \infty)$ be a function. Suppose that $T: X \rightarrow X$ be a self mapping satisfying the following conditions:

(i) for all $x, y \in X$

$$
\begin{gathered}
\alpha(x, y) d\left(T^{2} x, T^{2} y\right) \leq k \max \left\{d(x, y), d(T x, T y), d(x, T x), d\left(T x, T^{2} x\right),\right. \\
\left.d(y, T y), d\left(T y, T^{2} y\right)\right\}
\end{gathered}
$$

where $k \in[0,1)$;

(ii) $T$ is $\alpha$-admissible;

(iii) there exists $x_{0} \in X$ such that $\alpha\left(x_{0}, T x_{0}\right) \geq 1$;

(iv) $T$ is continuous or, orbitally continuous on $X$.

Then, $T$ has a fixed point in $X$. Further, if $T$ is an $\alpha^{*}$-admissible, then $T$ has a unique fixed point $z \in X$. Moreover, for any $x_{0} \in X$ if $x_{n+1}=T^{n+1} x_{0} \neq T^{n} x_{0}$ for all $n \in \mathbb{N} \cup\{0\}$, then $\lim _{n \rightarrow \infty} T^{n} x_{0}=z$.

Proof. Setting $F(\gamma)=\ln (\gamma), \gamma>0$. Obviously, $F \in \mathcal{F}$. Taking natural logarithm on both sides of (16), we obtain

$$
\begin{aligned}
& -\ln k+\ln \alpha(x, y) d\left(T^{2} x, T^{2} y\right) \\
& \leq \ln \left(\max \left\{d(x, y), d(T x, T y), d(x, T x), d\left(T x, T^{2} x\right), d(y, T y), d\left(T y, T^{2} y\right)\right\}\right),
\end{aligned}
$$

which implies that

$$
\tau+F\left(\alpha(x, y) d\left(T^{2} x, T^{2} y\right)\right) \leq F\left(M^{1}(x, y)\right)
$$

for all $x, y \in X$ with $x \neq y$ where $\tau=-\ln k$. This shows that $T$ is $\alpha$-F-convex contraction with $p=1$. Thus, all the conditions of Theorem 2 are satisfied and hence, $T$ has a unique fixed point in $X$.

The following is proved in Khan et al. ([10], [Theorem 2.2]) by extending convex contraction of type-2 (Istrăţescu [4]) to generalized convex contraction of type-2 in the setting of $b$-metric space .

Corollary 2. Let $(X, d)$ be a complete metric space and $\alpha: X \times X \rightarrow[0, \infty)$ be a function. Suppose that $T: X \rightarrow X$ be a self mapping satisfying the following conditions:

(i) for all $x, y \in X$

$$
\begin{aligned}
\alpha(x, y) d\left(T^{2} x, T^{2} y\right) \leq & \alpha_{1} d(x, y)+\alpha_{2} d(T x, T y)+\alpha_{3} d(x, T x)+\alpha_{4} d\left(T x, T^{2} x\right) \\
& \left.+\alpha_{5} d(y, T y)+\alpha_{6} d\left(T y, T^{2} y\right)\right\}
\end{aligned}
$$

where $0 \leq \alpha_{i}<1, i=1,2, \ldots, 6$ such that $\sum_{i=1}^{6} \alpha_{i}<1$;

(ii) $T$ is $\alpha$-admissible;

(iii) there exists $x_{0} \in X$ such that $\alpha\left(x_{0}, T x_{0}\right) \geq 1$;

(iv) $T$ is continuous or, orbitally continuous on $X$.

Then, $T$ has a fixed point in $X$. Further, if $T$ is $\alpha^{*}$-admissible, then $T$ has a unique fixed point $z \in X$. Moreover, for any $x_{0} \in X$ if $x_{n+1}=T^{n+1} x_{0} \neq T^{n} x_{0}$ for all $n \in \mathbb{N} \cup\{0\}$, then $\lim _{n \rightarrow \infty} T^{n} x_{0}=z$. 
Proof. Setting $F(\gamma)=\ln (\gamma), \gamma>0$. Obviously, $F \in \mathcal{F}$. For all $x, y \in X$ with $x \neq y$, we obtain

$$
\begin{aligned}
\alpha(x, y) d\left(T^{2} x, T^{2} y\right)= & d\left(T^{2} x, T^{2} y\right) \\
\leq & \alpha_{1} d(x, y)+\alpha_{2} d(T x, T y)+\alpha_{3} d(x, T x)+\alpha_{4} d\left(T x, T^{2} x\right) \\
& \left.+\alpha_{5} d(y, T y)+\alpha_{6} d\left(T y, T^{2} y\right)\right\} \\
\leq & k \max \left\{d(x, y), d(T x, T y), d(x, T x), d\left(T x, T^{2} x\right),\right. \\
& \left.d(y, T y), d\left(T y, T^{2} y\right)\right\}
\end{aligned}
$$

where $k=\sum_{i=1}^{6} \alpha_{i}<1$. Therefore, by above Corollary $1, T$ has a unique fixed point in $X$.

Corollary 3. Let $T$ be a continuous mapping on a complete metric space $(X, d)$ into itself. If there exists $k \in[0,1)$ satisfying the following inequality

$$
\begin{gathered}
d\left(T^{2} x, T^{2} y\right) \leq k \max \left\{d(x, y), d(T x, T y), d(x, T x), d\left(T x, T^{2} x\right),\right. \\
\left.d(y, T y), d\left(T y, T^{2} y\right)\right\}
\end{gathered}
$$

for all $x, y \in X$, then $T$ has a unique fixed point in $X$.

\section{Application}

In this section, we apply our result to establish an existence theorem forthe non-linear Fredholm integral equation and give a numerical example to validate the application of our obtained result.

Let $X=C[a, b]$ be a set of all real continuous functions on $[a, b]$ equipped with metric $d(f, g)=|f-g|=\max _{t \in[a, b]}|f(t)-g(t)|$ for all $f, g \in C[a, b]$. Then, $(X, d)$ is a complete metric space.

Now, we consider the non-linear Fredholm integral equation

$$
x(t)=v(t)+\frac{1}{b-a} \int_{a}^{b} K(t, s, x(s)) d s,
$$

where $t, s \in[a, b]$. Assume that $K:[a, b] \times[a, b] \times X \rightarrow \mathbb{R}$ and $v:[a, b] \rightarrow \mathbb{R}$ continuous, where $v(t)$ is a given function in $X$.

Theorem 3. Suppose that $(X, d)$ is a metric space equipped with metric $d(f, g)=|f-g|=\max _{t \in[a, b]} \mid f(t)-$ $g(t) \mid$ for all $f, g \in X$ and $T: X \rightarrow X$ be a continuous operator on $X$ defined by

$$
T x(t)=v(t)+\frac{1}{b-a} \int_{a}^{b} K(t, s, x(s)) d s .
$$

If there exists $k \in[0,1)$ such that for all $x, y \in X$ with $x \neq y$ and $s, t \in[a, b]$ satisfying the following inequality

$$
\begin{aligned}
|K(t, s, T x(s))-K(t, s, T y(s))| \leq k \max \{ & |x(s)-y(s)|, \mid T x(s)-T y(s), \\
& |x(s)-T x(s)|,\left|T x(s)-T^{2} x(s)\right|, \\
& \left.|y(s)-T y(s)|,\left|T y(s)-T^{2} y(s)\right|\right\},
\end{aligned}
$$

then the integral operator defined by (18) has a unique solution $z \in X$ and for each $x_{0} \in X, T x_{n} \neq x_{n}$ for all $n \in \mathbb{N} \cup\{0\}$, we have $\lim _{n \rightarrow \infty} T x_{n}=z$. 
Proof. We define $\alpha: X \times X \rightarrow[0, \infty)$ such that $\alpha(x, y)=1$ for all $x, y \in X$. Therefore, $T$ is $\alpha$-admissible. Setting $F \in \mathcal{F}$ such that $F(\gamma)=\ln (\gamma), \gamma>0$. Let $x_{0} \in X$ and define a sequence $\left\{x_{n}\right\}$ in $X$ by $x_{n+1}=T x_{n}=T^{n+1} x_{0}$ for all $n \geq 0$. By (18), we obtain

$$
x_{n+1}=T x_{n}(t)=v(t)+\frac{1}{b-a} \int_{a}^{b} K\left(t, s, x_{n}(s)\right) d s .
$$

We show that $T$ is $\alpha$-F-convex contraction on $C[a, b]$. Using (18) and (19), we obtain

$$
\begin{aligned}
\left|T^{2} x(t)-T^{2} y(t)\right| & =\frac{1}{|b-a|}\left|\int_{a}^{b} K(t, s, T x(s)) d s-\int_{a}^{b} K(t, s, T y(s)) d s\right| \\
\leq & \frac{1}{|b-a|} \int_{a}^{b}|K(t, s, T x(s))-K(t, s, T y(s))| d s \\
\leq & \frac{k}{|b-a|} \int_{a}^{b} \max \{|x(s)-y(s)|,|T x(s)-T y(s),| x(s)-T x(s) \mid, \\
& \left.\left|T x(s)-T^{2} x(s)\right|,|y(s)-T y(s)|,\left|T y(s)-T^{2} y(s)\right|\right\} d s .
\end{aligned}
$$

Taking maximum on both sides for all $t \in[a, b]$, we obtain

$$
\begin{aligned}
d\left(T^{2} x, T^{2} y\right)= & \max _{t \in[0,1]}\left|T^{2} x(t)-T^{2} y(t)\right| \\
\leq & \frac{k}{|b-a|} \max _{t \in[a, b]} \int_{a}^{b} \max \{|x(s)-y(s)|,|T x(s)-T y(s),| x(s)-T x(s) \mid, \\
& \left.\left|T x(s)-T^{2} x(s)\right|,|y(s)-T y(s)|,\left|T y(s)-T^{2} y(s)\right|\right\} d s \\
\leq & \frac{k}{|b-a|} \max \left[\max _{r \in[a, b]}\{|x(r)-y(r)|,|T x(r)-T y(r),| x(r)-T x(r) \mid,\right. \\
& \left.\left.\left|T x(r)-T^{2} x(r)\right|,|y(r)-T y(r)|,\left|T y(r)-T^{2} y(r)\right|\right\}\right] \int_{a}^{b} d s \\
& =k \max \left\{d(x, y), d(T x, T y), d(x, T x), d\left(T x, T^{2} x\right), d(y, T y), d\left(T y, T^{2} y\right)\right\} \\
& =k M^{1}(x, y) .
\end{aligned}
$$

Therefore

$$
\alpha(x, y) d\left(T^{2} x, T^{2} y\right) \leq k M^{1}(x, y) .
$$

Now, taking natural logarithm on both sides, we obtain

$$
-\ln k+\ln \left[\alpha(x, y) d\left(T^{2} x, T^{2} y\right)\right] \leq \ln M^{1}(x, y) .
$$

Thus, we obtain

$$
\tau+F\left(\alpha(x, y) d\left(T^{2} x, T^{2} y\right)\right) \leq F\left(M^{1}(x, y)\right),
$$

where $-\ln k=\tau$. This shows that $T$ is $\alpha$-F-convex contraction with $p=1$ for all $x, y \in X$ with $x \neq y$. Since $T$ is $\alpha$-admissible and $X=C[a, b]$ is complete metric space. Therefore, the iteration scheme (4.4) converges to some point $z \in X$, i.e., $\lim _{n \rightarrow \infty} x_{n} \rightarrow z$. By continuity of $T$, one can prove that $T$ has a fixed point, i.e., $T z=z$. Consequently, $\operatorname{Fix}(T) \neq \varnothing$. Also, for all $x, y \in \operatorname{Fix}(T), \alpha\left(z, z^{*}\right)=1$ follows that $T$ is $\alpha^{*}$-admissible. Thus, all the conditions of Theorem 2 are satisfied and hence, the integral operator $T$ defined by (18) has a unique solution $z \in X$. 
The following example shows the existence of unique solution of an integral operator satisfying all the hypothesis in Theorem 3, however, one can also check that the following example does not satisfy F-contraction.

Example 9. Let $X=C[0,1]$ be a set of all continuous functions defined on $[0,1]$ equipped with metric $d(f, g)=|f-g|=\max _{t \in[0,1]}|f(t)-g(t)|$ for all $f, g \in X$. Let $T: X \rightarrow X$ be the operator defined by

$$
T x(t)=v(t)+\int_{0}^{1} K(t, s, x(s)) d s .
$$

Therefore,

$$
\begin{aligned}
T^{2} x(t) & =v(t)+\int_{0}^{1} K(t, s, T x(s)) d s \\
& =v(t)+\int_{0}^{1} K\left(t, s, v(t)+\int_{0}^{1} K(t, s, x(t)) d s\right) d s .
\end{aligned}
$$

Letting $v(t)=\frac{8}{15} t^{2}$ and $K(t, s, x(s))=\frac{1}{4} t^{2}(1+s)\left(x^{2}(s)+1\right)$. Then, (21) becomes

$$
T x(t)=\frac{8}{15} t^{2}+\int_{0}^{1} \frac{1}{4} t^{2}(1+s)\left(x^{2}(s)+1\right) d s .
$$

Then, (i) $v(t)$ and $K(t, s, x(s))$ are continuous,

(ii) $\max \frac{1}{4}\left|t^{2}(1+s)\right| \leq \frac{1}{2}$ for all $(t, s) \in[0,1] \times[0,1]$,

(iii) $T x \in X$ for all $x \in X$,

(iv) For all $x, y \in X$ with $x \neq y$ and $(t, s) \in[0,1] \times[0,1]$ and using (21) and (22), we obtain

$$
\begin{aligned}
|T x(t)-T y(t)| & =\left|\int_{0}^{1} K(t, s, x(s)) d s-\int_{0}^{1} K(t, s, y(s)) d s\right| \\
& \left.\leq \int_{0}^{1} \mid K(t, s, x(s))-K(t, s, y(s)) d s\right) \mid d s \\
& =\int_{0}^{1}\left|\frac{t^{2}(1+s)}{4}\left(x^{2}(s)-y^{2}(s)\right)\right| d s
\end{aligned}
$$

Taking maximum on both sides for all $t \in[a, b]$, we obtain

$$
\begin{aligned}
|T x-T y| & =\max _{t \in[0,1]}|T x(t)-T y(t)| \\
& \leq \max _{t \in[0,1]} \int_{0}^{1}\left|\frac{t^{2}(1+s)}{4}\left(x^{2}(s)-y^{2}(s)\right)\right| d s \\
& \leq \frac{1}{2} \max _{\rho \in[0,1]}\left|x^{2}(\rho)-y^{2}(\rho)\right| \int_{0}^{1} d s \\
& \leq|x-y|
\end{aligned}
$$


From the above, one can verify that the integral operator $T$ is not an F-contraction. Also, we have

$$
\begin{aligned}
\left|T^{2} x(t)-T^{2} y(t)\right|= & \left|\int_{0}^{1} K(t, s, T x(s)) d s-\int_{0}^{1} K(t, s, T y(s)) d s\right| \\
= & \mid \int_{0}^{1} K\left(t, s, v(t)+\int_{0}^{1} K(t, s, x(t)) d s\right) d s \\
& -\int_{0}^{1} K\left(t, s, v(t)+\int_{0}^{1} K(t, s, y(t)) d s\right) d s \mid \\
\leq & \int_{0}^{1} \mid K\left(t, s, v(t)+\int_{0}^{1} K(t, s, x(t)) d s\right) d s \\
& -K\left(t, s, v(t)+\int_{0}^{1} K(t, s, y(t)) d s\right) \mid d s \\
= & \int_{0}^{1}\left|\frac{t^{2}(1+s)}{4} \int_{0}^{1}\left[\frac{t^{2}(1+s)}{8}\left(x^{2}(s)-y^{2}(s)\right)\right] d s\right| d s \\
\leq & \int_{0}^{1} \int_{0}^{1}\left|\left[\frac{t^{2}(1+s)}{4}\right]^{2}\left(x^{2}(s)-y^{2}(s)\right)\right| d s d s .
\end{aligned}
$$

Taking maximum on both sides for all $t \in[a, b]$, we obtain

$$
\begin{aligned}
\left|T^{2} x-T^{2} y\right| & =\max _{t \in[0,1]}\left|T^{2} x(t)-T^{2} y(t)\right| \\
& \leq \max _{t \in[0,1]} \int_{0}^{1} \int_{0}^{1}\left|\left[\frac{t^{2}(1+s)}{4}\right]^{2}\left(x^{2}(s)-y^{2}(s)\right)\right| d s d s \\
& \leq \frac{1}{4} \max _{\rho \in[0,1]}\left|x^{2}(\rho)-y^{2}(\rho)\right| \int_{0}^{1} \int_{0}^{1} d s d s \\
& =\frac{1}{4}\left|x^{2}-y^{2}\right| \leq \frac{1}{2}|x-y| \leq \frac{1}{2} M^{1}(x, y) \\
& =e^{-\tau} M^{1}(x, y),
\end{aligned}
$$

where $\ln \frac{1}{2}=-\tau$. Setting $\alpha: X \times X \rightarrow[0, \infty)$ by $\alpha(x, y)=1$ for all $x, y \in X$ and $F \in \mathcal{F}$ such that $F(\gamma)=\ln (\gamma), \gamma>0$. Therefore, we obtain

$$
\alpha(x, y)\left|T^{2} x-T^{2} y\right| \leq e^{-\tau} M^{1}(x, y) .
$$

Taking natural logarithm on both sides, we obtain

$$
\tau+\ln \alpha(x, y) d\left(T^{2} x, T^{2} y\right) \leq \ln M^{1}(x, y),
$$

that is,

$$
\tau+F\left(\alpha(x, y) d\left(T^{2} x, T^{2} y\right)\right) \leq F\left(M^{1}(x, y)\right) .
$$

This shows that $T$ is $\alpha-F$-convex contraction with $p=1$ for all $x, y \in X$. Thus, all the conditions of Theorem 3 are satisfied and therefore, the integral Equation (21) has a unique solution. One can verify that $x(t)=t^{2}$ is the exact solution of the equation (21). Using the iteration scheme (20), (23) becomes

$$
x_{n+1}=T x_{n}(t)=\frac{8}{15} t^{2}+\frac{1}{4} \int_{0}^{1}\left[t^{2}(1+s)\left\{x_{n}^{2}(s)+1\right\}\right] d s .
$$


Letting $x_{0}(t)=0$ be an initial solution. Putting $n=0,1,2, \ldots$, successively in (24), we obtain

$$
\begin{array}{rll}
x_{1}(t)=0.90833333 t^{2}, & x_{2}(t)=0.98396470 t^{2}, & x_{3}(t)=0.99708377 t^{2} \\
x_{4}(t)=0.99946614 t^{2}, & x_{5}(t)=0.99990215 t^{2}, & x_{6}(t)=0.99998206 t^{2} \\
x_{7}(t)=0.99999671 t^{2}, & x_{8}(t)=0.99999940 t^{2}, & x_{9}(t)=0.99999985 t^{2} \\
x_{10}(t)=0.99999998 t^{2}, & x_{11}(t)=t^{2} . &
\end{array}
$$

Therefore, $x(t)=t^{2}$ is the unique solution.

Author Contributions: All authors contributed equally in writing this article. All authors read and approved the final manuscript.

Acknowledgments: The authors are thankful to the anonymous referee for their valuable constructive comments and suggestions to improve the quality of the manuscript.

Conflicts of Interest: The authors declare no conflict of interest.

\section{References}

1. Banach, S. Sur les opérations dans les ensembles abstraits et leur application aux équations intégrales. Fund. Math. 1922, 3, 133-181. [CrossRef]

2. Ćirić, L.B. Generalized contractions and fixed point theorems. Publ. Inst. Math. 1971, 12, $19-26$.

3. Ćirić, L.B. A generalizatin of Banach's contraction principle. Proc. Am. Math. Soc. 1974, 45, 267-273. [CrossRef]

4. Istrăţescu, V.I. Some fixed point theorems for convex contraction mappings and convex nonexpansive mappings (I). Liberta Math. 1981, 1, 151-163.

5. Alghamdi, M.A.; Alnafei, S.H.; Radenovic, S.; Shahzad, N. Fixed point theorems for convex contraction mappings on cone metric spaces. Math. Comput. Model. 2011, 54, 2020-2026. [CrossRef]

6. Ghorbanian, V.; Rezapour, S.; Shahzad, N. Some ordered fixed point results and the property $(P)$. Comput. Math. Appl. 2012, 63, 1361-1368. [CrossRef]

7. Latif, A.; Sintunavarat, W.; Ninsri, A. Approximate fixed point theorems for partial generalized convex contraction mappings in $\alpha$-complete metric spaces. Taiwan J. Math. 2015, 19, 315-333. [CrossRef]

8. Miandarag, M.A.; Postolache, M.; Rezapour, S. Approximate fixed points of generalizes convex contractions. Fixed Point Theory Appl. 2013, 255, 1-8.

9. Miculescu, R.; Mihail, A. A generalization of Istrăţescu's fixed piont theorem for convex contractions. arXiv 2015, arXiv:1512.05490v1.

10. Khan, M.S.; Singh, Y.M.; Maniu, G.; Postolache, M. On generalized convex contractions of type-2 in b-metric and 2-metric spaces. J. Nonlinear Sci. Appl. 2017, 10, 2902-2913. [CrossRef]

11. Khan, M.S.; Singh, Y.M.; Maniu, G.; Postolache, M. On $(\alpha, p)$-convex contraction and asymptotic regularity. J. Math. Comput. Sci. 2018, 18, 132-145. [CrossRef]

12. Wardowski, D. Fixed points of a new type of contractive mappings in complete metric spaces. Fixed Point Theory Appl. 2012, 94, 1-11. [CrossRef]

13. Samet, B.; Vetro, C.; Vetro, P. Fixed point theorems for $\alpha-\psi$-contractive type mappings. Nonlinear Anal. 2012, 75, 2154-2165. [CrossRef]

14. Karapinar, E.; Kumam, P.; Salimi, P. On $\alpha-\psi$-Meir-Keeler contractive mappings. Fixed Point Theory Appl. 2013, 94, 1-12. [CrossRef]

15. Karapinar, E. $\alpha-\psi$-Greaghty contraction type mappings and some related fixed point results. Filomat 2014, 28, 37-48. [CrossRef]

16. Alsulami, H.H.; Chandok, S.; Taoudi, M.A.; Erhan, I.M. Some fixed point theorems for $(\alpha, \psi)$-rational type contractive mappings. Fixed Point Theory Appl. 2015, 97, 1-12. [CrossRef]

(C) 2018 by the authors. Licensee MDPI, Basel, Switzerland. This article is an open access article distributed under the terms and conditions of the Creative Commons Attribution (CC BY) license (http:/ / creativecommons.org/licenses/by/4.0/). 